\title{
Promoting Connectedness through Whole-School Approaches: A Qualitative Study
}

\begin{abstract}
Purpose: School connectedness, or a sense of belonging to the school environment, is an established protective factor for child and adolescent health, education, and social well-being. While a comprehensive, whole-school approach that addresses the school organisational environment is increasingly endorsed as an effective approach to promote connectedness, how this approach creates a sense of belonging in the school environment requires systematic in-depth exploration. This paper aims to address these issues.
\end{abstract}

Design/methodology/approach: This study examines the influence on school connectedness of a whole-school approach to promote health in school, using a qualitative case study method. Three school communities in southeast Queensland, Australia, were investigated as case studies in order to formulate a theoretical model of how health promotion approaches can build school connectedness.

Findings: This study found that a health promotion approach builds school connectedness by encouraging a 'whole-school' orientation designed to foster interaction among members of the entire school community. Specific activities that promoted interaction were school-wide activities involving the entire school community and, at the classroom level, 'whole-class' activities in which students and staff worked together on activities that created links between the two groups, such as collaborative curriculum planning. The 'whole-school' emphasis on partnerships 
between staff and students and parents was also important, particular with its focus on initiating and sustaining school-community partnerships.

Originality/value: The findings are important, since they validate a whole-school approach to building school connectedness, and address an important gap in the literature about how to promote school connectedness and thereby protect the wellbeing of children and adolescents.

Keywords: School, Connectedness, Health, Promotion, Environment, Australia

Paper type: Research paper 


\section{Promoting Connectedness through Whole-School Approaches: \\ A Qualitative Study}

\section{Introduction}

School connectedness, a sense of belonging to the school environment, is an established protective factor for child and adolescent health, education, and social well-being. A sense of connection and belonging to the school environment is widely recognised as promoting children’s and adolescents’ mental and emotional well-being (Bond et al., 2007; Hawkins et al., 2005; Resnick et al., 1997; Rutter et al., 1979) and protecting against health-compromising behaviours such as substance use, violence, sexuality, heavy alcohol use, and intention to drink alcohol (Bisset et al., 2007; Kliewer and Murrelle, 2007; Patton et al., 2006; Springer et al., 2006). Most recently, a sense of connectedness and school engagement has also been associated with healthpromoting behaviours among secondary school students, including physical activity, nutrition, and use of bicycle helmets (Carter et al., 2007).

Children's and adolescents' perceptions of belonging to a school community are positively associated with academic achievement and engagement (Bond et al., 2007; Lonczak et al., 2002; Pittman and Richmond, 2007), the completion of secondary school (Bond et al., 2007), and positive development into adulthood (Youngblade et al., 2007).

School connectedness is increasingly recognised as an important characteristic of a school's social environment (Bond et al., 2007; Carter et al., 2007), as is the need for 
positive reinforcement in multiple contexts, such as in family and community settings. All of these factors influence child and adolescent health (Youngblade et al., 2007) and their perceptions of their school environment (Shochet et al., 2007). Thus, contemporary theory conceives and defines school connectedness as an ecological concept (Rowe et al., 2007).

An ecological view of school connectedness takes into account the quality of connections among multiple groups in the school community and recognises the cohesiveness among different groups, such as students, families, school staff, and representatives of health and community agencies. This cohesiveness is characterised by strong social bonds, featuring high levels of interpersonal trust and norms of reciprocity, otherwise known as social capital (Kawachi and Berkmann, 2000; Putnam, 1995; Wilkinson, 1996). Social capital is a feature of social relationships in a school community that provides the building blocks for connectedness. Accumulation of social capital has been shown to lead to an elimination or reduction in social conflict (e.g. bullying), an abundance of associations that bridge social divisions (e.g. tolerance of diverse cultures), and the presence of systems that promote conflict management (e.g. a fair behaviour management system whereby processes for resolving disputes involve investigation and/or discussion) (Kawachi and Berkmann, 2000).

Although school connectedness is widely accepted as important, how to promote it remains poorly understood. Following several attempts to implement piecemeal strategies in order to promote connectedness, it now appears that a comprehensive whole-school approach to promoting school connectedness holds the most promise 
(Battistich et al., 2004; Hawkins et al., 2005; Youngblade et al., 2007). Such an approach requires an organisational perspective that encompasses structural elements of the whole school and includes the family and broader community context as part of the school community.

A growing body of evidence indicates that a whole-school approach, embodied by the health-promoting school (HPS) model, is effective in the school setting for promoting connectedness that features social capital (Sun and Stewart, 2007). The HPS model is a framework that addresses the school as a whole, including curriculum, teaching, and learning; school policies, procedures, and organisation; physical and social environment, and links with families and the broader community, including health services and community agencies (Clift and Bruun Jensen, 2006; Rowe et al., 2007; Sun and Stewart, 2007). In their prospective intervention study comparing 10 intervention and control schools, Sun and Stewart (2007) found that the HPS model was effective in promoting school connectedness, which was characterised by social capital resources such as trust and safety, perceptions of being valued, and working relationships among staff.

New developments in knowledge about the effectiveness of the HPS model have created opportunities for detailing the mechanisms by which a comprehensive approach promotes school connectedness, which have been discussed by Rowe et al., (2007) and by Stewart (2008). The present article presents the results of a qualitative research study that investigated how a whole-school approach, embodied by the HPS model, promotes school connectedness. 


\section{Description of the Research}

This research involved case studies in three school communities in southeast Queensland, Australia, conducted between October 2000 and April 2002. The study formed part of an evaluation of a program, the 'Western Gateway Health Promoting Schools Grant Scheme', which aimed to increase students' sense of school connectedness through implementation of the HPS approach in a school setting. The program was coordinated by a public health agency (Queensland Health), and it involved supporting 10 school communities with a grant of AU\$28,000 over three years. The program also included professional development workshops and support from a program manager who provided expertise and links to health resources to assist schools in implementing the approach. Three school communities were selected from the program to be researched in depth in order to investigate the influence of the HPS approach on school connectedness. The three communities were chosen as representative of the diversity of the 10 schools supported under the scheme.

The aim of the research was to investigate: (1) what 'structural' aspects of the HPS approach, defined as tangible artifacts or programs within the school community, influence school connectedness; and (2) what 'process' aspects of the HPS approach, defined as the methods of operationalising structures, influence school connectedness at both the school and classroom levels. The investigation was guided by a conceptual framework (Figure 1) developed from an in-depth, interdisciplinary review of the literature dealing with the influences of the HPS approach on school connectedness. The present review drew from both school and community literature and included both data-based evidence and theoretical insights (Rowe et al., 2007). 


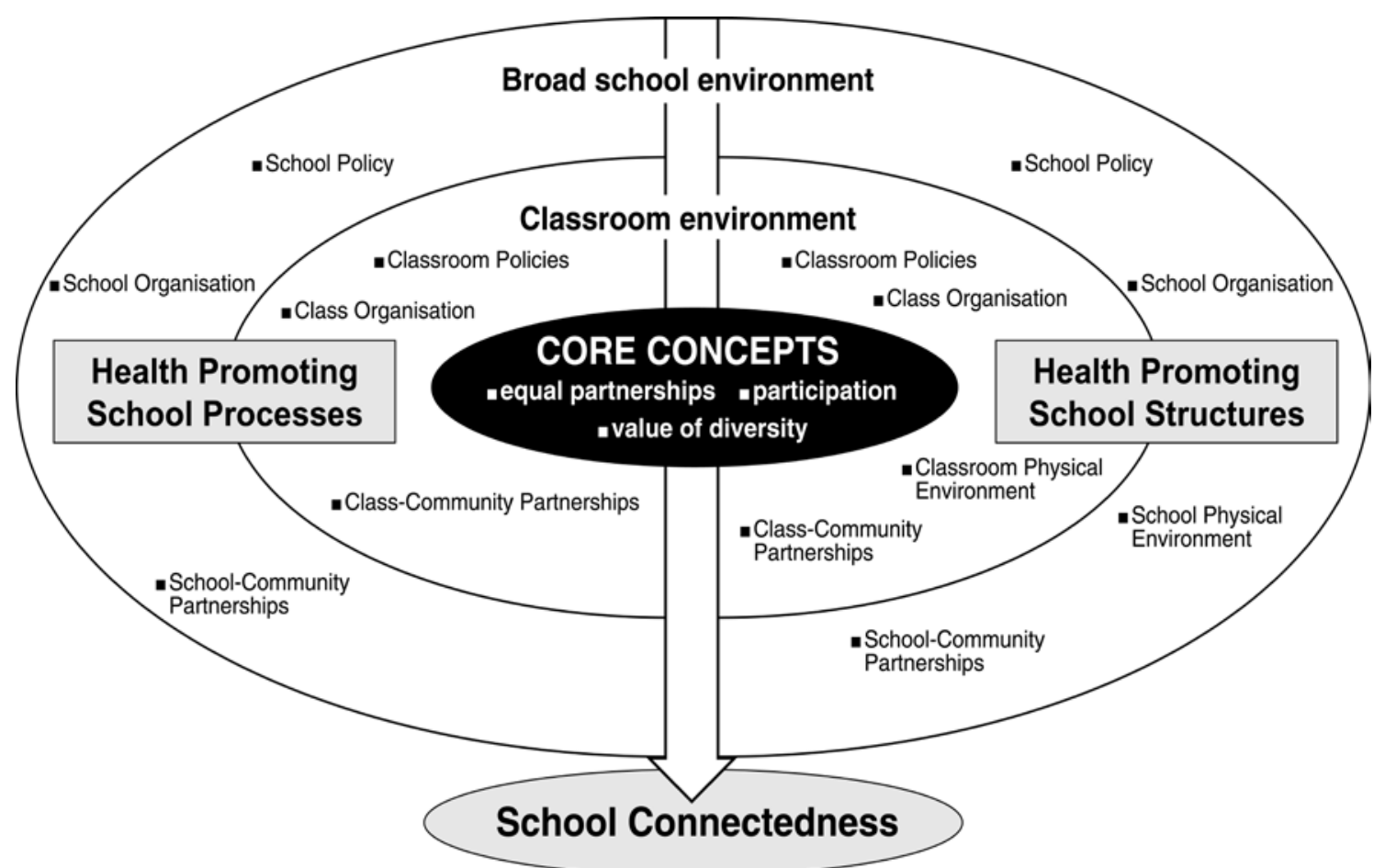

Figure 1. Conceptual Framework of the Influence of the Health-Promoting School Approach on School Connectedness

\section{Methods}

Case study methodology was used in this study of school communities (Patton, 1990; Yin, 1994). The school community, including school staff, students, parents and carers, as well as representatives of health service and community agencies formed the unit of analysis in this case study design. A two-phased, time-series design was employed in each of the three schools, such that relationships between aspects of the HPS approach and indicators of school connectedness could be followed in the over a certain period of time. 
Data on these relationships were collected using in-depth interviews with representatives of key groups within the school community, such as school staff, parents, students, and health and community workers. In addition, student focus groups and documentary evidence, such as school progress reports and observations of HPS activities, were important sources of data. All of these data sources were corroborated with each other to gain a comprehensive understanding of the impact of the HPS approach on school connectedness (Yin, 1994).

A purposive sampling framework was used to select interviewees, such that those who were interviewed were the most involved in the implementation of the HPS approach in that school (Patton, 1990). In response to conflicting or insubstantial data in the first phase of the study, this sampling process was used to follow up with information-rich sources to explore further phenomena in the second data collection phase.

Data were collected on the implementation of HPS structures and processes. These structures and processes reflect the key concepts of participation, equal partnerships, and value of diversity as well as their effect on school connectedness. The structures and processes were examined both in the classroom and broader school environment. Evidence of school connectedness was collected through the social capital constructs of trust, tolerance of diversity, perceptions of being valued, mutual reciprocity, and participation in the school environment (Onyx and Bullen, 2000). Data on 'ecological indicators' of school connectedness, such as absenteeism and bullying, were also collected (Lochner et al., 1999). 


\section{School Case Studies}

A secondary school, primary school, and special needs school were selected in order to explore the implementation of the HPS approach within diverse school organisation contexts. The special needs school provided a setting for students with intellectual, physical, and behavioural disabilities. Consistent with a theory-building approach, this study selected diverse school communities in order to investigate a wide variety of settings and thereby develop a richer theoretical model for how the HPS approach influences school connectedness (Yin, 1994). Cases were also selected based on the intensity with which schools were implementing the HPS approach, in order to ensure that the most could be learned from the case study (Miles and Hubermann, 1994; Patton, 1990).

\section{Data Analysis}

The analysis of data focused on identifying relationships between the HPS approach and school connectedness in each school case study. These data were then used in a cross-case analysis in order to develop a theoretical model. The analysis categorised data into themes and categories based on, but not limited to, the conceptual framework that guided data collection. The coding process was guided by decision rules related to the relevance of the data (i) to the HPS approach and (ii) to school connectedness defined by the study, and also, to the development of theory regarding the relationship between HPS and school connectedness. For example, the recognition by interviewees of a peer support program being implemented both as a 
component of the organisational structure of the HPS approach, and also contributing to the development of multi-age student friendship groups (an ecological indicator of school connectedness), were coded under the relevant HPS and school connectedness themes, with the extraction of data categories to explain the relationship between these phenomena.

To ensure the validity of the findings, data triangulation and decision rules for inclusion, for example, data confirmed by two methodological sources, guided the selection of themes and categories entered into data matrix displays (Miles and Hubermann, 1994). These displays enabled the identification and explication of theoretical relationships between the HPS approach and school connectedness.

\section{Results}

The research findings reported here draw on data from 38 in-depth interviews and 12 focus groups conducted across three school communities in Ipswich, Queensland, Australia. Ipswich is an urban locale with a socio-economic status comparable to that of other Queensland regions, and with a much more diverse multicultural population than surrounding areas. At the beginning of each interview and focus group, respondents were asked about the implementation of the HPS approach in their school, and the questions paid particular attention to structures and processes. Participants then responded to a series of questions on their perceptions of school connectedness based on (1) the social capital indicators of trust, perceptions of being valued, mutual reciprocity, and participation; and (2) ecological indicators, such as 
bullying, students that 'intervene' for others being bullied, exclusions/suspensions/detentions, absenteeism, school satisfaction, vandalism, littering, a fair behaviour management system, associations that bridge social divisions (cross-cultural relationships, friendship groups that span across classes), and well-functioning committees. Several relationships between the HPS approach and school connectedness emerged from the data, and these relationships showed varying degrees of 'relatedness' to the HPS approach. The data were then analysed across all three case studies using a cross-case analysis, and a theoretical model of the influence of the HPS approach on school connectedness was developed.

\section{Relationships between the Health-Promoting School approach and School Connectedness}

Several different relationships between the HPS approach and indicators of school connectedness were detected in the school communities, and these different relationships reflected how each school implemented the approach. Table 1 below provides the framework for a detailed discussion of the findings from the cross-case analysis across the three schools; these findings provide information on both the structures and processes that influence indicators of school connectedness at the broad level of the school as a whole, and at the level of the individual classroom. The school-level results will be discussed first, followed by the classroom-level results. 


\begin{tabular}{|c|l|}
\hline Structural aspects & \begin{tabular}{l} 
Policies and Organisational Structures to Prevent \\
Bullying \\
Peer Support Programs \\
Extra-Curricular Activities \\
Support Structures for School Staff \\
A Fair Behaviour Management System \\
A 'Welcoming' Environment \\
Significance of School-Community Partnership \\
Structures \\
\hline Processes
\end{tabular} \\
$\begin{array}{l}\text { Significance of School-Community Partnerships } \\
\text { School Partnerships with Parents } \\
\text { School Partnerships with School Staff } \\
\text { School Staff-Parent Partnership }\end{array}$ \\
\hline
\end{tabular}

Table 1. Whole-School Level Structures and Processes that Influence Indicators of School Connectedness 


\begin{tabular}{|c|l|}
\hline Structural aspects & $\begin{array}{l}\text { Classroom level } \\
\text { Significance of Class Organisation Activities } \\
\text { Importance of Class-Community Partnerships }\end{array}$ \\
\hline Processes & $\begin{array}{l}\text { Significance of Processes of Working Together } \\
\text { Significance of Class-Community Partnerships }\end{array}$ \\
\hline
\end{tabular}

Table 2. Classroom Level Structures and Processes that Influence Indicators of School Connectedness

\section{Structural Aspects of the Health-Promoting School - at School Level}

\section{Policies and Organisational Structures to Prevent Bullying}

A range of school policies and structures to prevent bullying that also promoted various indicators of school connectedness were identified in all school settings. Through the promotion of perceptions of safety and reduced bullying in the school environment, behaviour management policies and safety policies were important in promoting school connectedness. Several other school organisational structures also contributed to these indicators. Multi-strategic approaches to prevent bullying, such as increased teacher supervision in the school environment during lunch hours, professional development of school staff in bullying and behaviour management, use of student-to-student approaches such as the 'peacekeepers' program and the 'buddy system', and related activities held in the lunch hour, all contributed to less bullying. In particular, the 'peacekeepers' program and 'buddy system', in which students intervene in minor bullying as a 'peacekeeper' or 'buddy', helped to reduce bullying. These findings reinforce the importance of a range of strategies encompassing school 
policy and organisational environment that not only reduce bullying, but prevent it from occurring.

\section{Peer Support Programs}

Peer support programs were an organisational structure implemented mainly in the primary school setting. The present study found them to increase two indicators of school connectedness: student friendship groups that bridge social divisions, and students’ perceptions of being valued. By grouping students into multi-aged groups, peer support programs contributed to the development of student friendship groups that bridged social divisions and spanned different years. As a part of a curriculum where students tutored their peers, it contributed to school staff valuing students, by allowing students to demonstrate skills outside of the academic curriculum, such as demonstration of leadership skills. This is illustrated in the following quote from the primary school case study:

There are children who have great difficulties who can, when you can see them doing something really well, you sort of build up on that and so that value is there, one boy comes to mind with peer support who has terrible behaviour problems, but when he took on the responsibility as a peer support manager, he was outstanding and - to just to see the difference because we gave him that opportunity to show what he was like. (School Staff Member A)

\section{Extra-Curricular Activities}

Extra-curricular activities that were based on students' interests and activities and in which students and school staff participate together contributed significantly to school 
connectedness in all of the schools examined. This may be due to the fact that these activities promoted student participation in the school environment and the development of student friendship groups, leading to increased student satisfaction with the school. This relationship between extra-curricular activities and connectedness emerged when students contributed to, and helped to determine, the types of extra-curricular activities that reflected their interests. Activities in which students and school staff participated together, such as student-teacher games, had a particularly powerful effect on connectedness. The effect of these games was particularly notable in the special needs school shown by the quote below from a teaching staff member:

Often during playground time, I'll get in for a game of cricket and bat and they go, "Oh God”, roll their eyes because they know I'm no good at sports....and I'll ham it up with the bowling... and they just go, “Oh!” and I'll say “Are you laughing at me?” And yes, and I mean it’s that lovely sense of fun and I guess that's often what connects you to the students. 'Cause there are certain staff that connect well and I am talking about the seniors particularly, there are certain staff that connect well with the seniors... and they are the ones that are prepared to get in there and they don't talk down to the students, they talk with students. And yes, they're prepared to get in there and have a game of cricket or look at something with the student, value the student. Just have that respect, I guess that's what it comes down to as well, both sides respecting one another. (School Staff Member B)

\section{Support Structures for School Staff}

Professional support structures for school staff, such as collaborative curriculum planning, were found in all three schools to contribute to various indicators of school connectedness. Activities such as staff social activities also contributed to staff 
perceptions of mutual reciprocity, helping school staff get along better with one another, and staff members' perceptions of being valued by their colleagues. These indicators, in turn, particularly in the secondary school, contributed to the emotional 'safety' of the school staff. The structures and activities discussed demonstrate ways to develop supportive school staff relationships and highlight the importance of these relationships for the connectedness of the school community and is illustrated by the following quote from a school staff member at the special needs school:

\footnotetext{
I think that's why I'd like to see a lot more of that [collaborative curriculum planning]. We all tend to work in our isolated rooms and it is lovely to start working with the other teachers, with the other classes. I think it helps with the planning and helps with the... just that whole feeling of connectedness; that we all belong as a community together, where we all ... feel valued. (School Staff Member B)
}

\section{A Fair Behaviour Management System}

This study found different elements of a fair behaviour management system to promote different indicators of school connectedness in all three school contexts. A fair behaviour management system contributed to school connectedness by building and reinforcing important aspects of mutual reciprocity, in addition to being an ecological indicator of school connectedness itself. A fair behaviour management system, as defined in this research, was found to be a system whereby processes for resolving disputes in the school environment involved investigation and/or discussion. A school behaviour management system that contributed to these indicators also included other elements: it meted out 'mild' punishment to bullies, it recognised positive behaviour through positive reinforcement, and it recognised the impact of the 
school environment on student behaviour, for example, by counselling staff on how they should model good behaviour in how they speak to students. At the same time, this study found that a fair behaviour management system was one in which behaviour was also seen to depend on the individual student. In other words, a fair behaviour management system that contributes to school connectedness places the responsibility for student behaviour on both the individual student and the school environment.

An individualised behaviour management system for each student in the school was found to contribute to perceptions of a fair behaviour management system. However, these results in favour of an individually-based management system conflict with our findings that indicate the importance of a consistent and clear behaviour management system applied uniformly to all students. The individualised system was perceived by staff to be fair in the special needs school, and interviews with staff indicated this was because it allowed student behaviour to be managed by a classroom staff member who 'knows the student the best'.

This study therefore suggests that the optimal behaviour management system combines elements that are uniform across the entire school, with elements that the classroom teacher individualises for students. This type of system could be managed consistently by the entire school staff as long as they are familiar with each student's individualised behaviour plan. The special needs school analysed in this study was developing such a system. Staff across the entire school had begun to communicate and share ideas about the individualised behaviour management plans of students to ensure that the students were dealt with in a consistent way. This process made an 
unintended, but significant, contribution to the staff perception that the behaviour management in the school was fair. Such as system therefore serves as a model that can be transposed into mainstream school systems.

\section{A 'Welcoming' Environment}

A 'welcoming' environment was another aspect of the school's organisational and environmental structure that contributed significantly to community agency representatives' perceptions of school connectedness. In particular, given the multicultural diversity in all the schools, a welcoming environment for different cultures (including support for the needs of all school community members) contributed to community agency representatives' perceptions that diversity was tolerated and to perceptions of being valued. For example, in the primary school, the study found that support for, and welcoming of, parents and students from diverse backgrounds contributed to a school environment in which people felt respected and valued. These findings explain the usefulness of using 'tolerance of diversity' as an indicator of school connectedness. A welcoming environment led parents to help in the school environment, and it thereby contributed strongly to indicators of participation, trust, and mutual reciprocity between parents and staff. Interviewees described a welcoming school environment as 'a welcome social environment where the principal and school staff are positive, friendly, happy, always say hello, call parents by their first name, and don't 'brush people off'”. A welcoming physical environment, such as having a small campus where new and potentially timid students and visitors can find their way around, was also found to contribute to indicators of school connectedness. These findings provide insight into the elements that encourage participation in the 
school community, particularly when parents and members of the school community come from diverse cultural backgrounds.

\section{Significance of School-Community Partnership Structures}

School-community partnership structures at both the 'micro' and 'macro' levels were found to be significant in promoting school connectedness. At the micro level, HPS committees contributed to indicators of school connectedness and contributed to the participation of community members, mainly parents, to the school environment. At the macro level, partnerships with health services, community agencies, and parents contributed to indicators of mutual reciprocity between the school and these groups and school staff perceptions of value of them. The following quote illustrates the mutual reciprocal relationships built between the primary school and community agency representatives and the importance of these relationships for school connectedness:

I just think it's a feeling of well-being amongst all of us that they [community agency representatives] feel that their contribution is valued and worthwhile - it's not just given...we invite them and there's no strings attached. Our children write thank you letters to our community whether they gave or not, it's not really an issue about giving, but it's an issue about belonging. (Community Agency Representative A)

At the macro level, whole-school community activities were powerful in promoting school connectedness. Whole-school community activities based on inclusion encouraged the participation of all members of the school community; notably, they encouraged participation of students of all abilities and the participation of non- 
teaching school staff, including grounds staff and cleaning staff. The special needs school also indicated that it tolerated diversity through its whole-school activities, which actively encouraged and included students from different economic circumstances. Whole-school community activities contributed to school satisfaction and such ecological indicators of school connectedness as 'school pride'. For example, an activity in which students engraved their identities into the pavers of a Kids Café had a powerful impact, as illustrated by the following quotes from a speech by a student at a dedication ceremony to open a Kids Café in the primary school case study:

I never imagined I'd be able to return to this school and speak so proudly about the pavers that helped build Kids Café, about all the words and phrases engraved on them by lots of different people, to make the floor that we will walk on more precious than any other school...when I say that this school is not made special merely with bricks and mortar, or in this case pavers, but with the hearts, minds, and dedication of those who have walked here and in the future.

The student continued:

Having left last year, I realise now that it was a special time being at this primary school because as the saying goes, 'We all pass this way but once.' I'm glad my life has led me through [Primary School] and I'm proud to have been able to engrave my initials in this place, as [Primary School] is engraved in my heart. (Student A)

School dedication ceremonies to open new facilities were particularly significant symbolic events for the entire school community and led to high participation of students, parents, staff and health service and community agency representatives in the school environment. They also contributed to a sense of school satisfaction, 
recognition in the broader community, and a feeling among members of the school community that they are 'presenting something they are proud of'. Similarly, activities that recognise student achievement and celebrate both the school community and student achievement, or other aspects of the school community that are valued, promoted high participation of students, parents and staff and ecological indicators of school connectedness.

\section{Process aspects of the Health-Promoting School - at School Level}

\section{Significance of School-Community Partnerships}

School-community partnership processes that encouraged participation of all school members were the most powerful in promoting school connectedness in all three schools in this study. At the micro level, HPS committee processes that clearly valued all members' contributions influenced indicators of a well-functioning committee, parents' perceptions of value, and mutual reciprocity between committee members. This is evidenced by the following quote from a parent from the secondary school case study:

I think probably the HPS committee values my input and participation more so than the school, but I think the school appreciates my input as well. (Parent A)

At the macro level, school-community partnerships characterised by mutual reciprocity formed the basis of the development of other indicators of school connectedness such as perceptions of being valued, trust and school satisfaction. 
Mutual reciprocal relationships between school staff and students had a particularly strong influence on students’ sense of belonging to the school environment.

\section{School Partnerships with Parents}

Processes related to partnerships with parents, in which parents were encouraged to help in the school community contributed to their participation in the school environment and their perception of being valued, as well as to feelings of mutual reciprocity between parents and school staff. Parents who demonstrate commitment to the school community through helping and providing support for the school contribute to staff perceptions of mutual reciprocity and value of parents. This, in turn, contributes to parents’ perceptions of being valued. In particular, parents felt valued when their support for the school was recognised and praised. Processes that gave parents a voice in the school community also contributed to their perceptions of being valued, particularly when the school community 'listens and does not dismiss their opinions' and 'thinks about their [parents'] opinions and acts on them where they can'. These processes provide insight into the specific elements of schoolcommunity partnerships that contribute to parents' participation, support, and perceptions of value in the school community. Through their effects on parents and parental involvement in the school, these elements affect school connectedness.

\section{School Partnerships with School Staff}

School-community partnership processes with school staff strengthened school staff participation and support for HPS activities in the school environment. School staff 
supported the activities if there were perceived benefits, they were well-managed, and were completed without too much disruption or time-wasting. Other important conditions for school staff participation in, and support of, the activities were that the activities be incorporated into everyday learning, such that students perceived them to be a learning experience.

School staff members who are interested in and committed to students and the school community were highly valued within the school environment. Such staff members were described in the present study as those who offer numerous educational opportunities, change their teaching methods to suit students, teach all students and 'not just part of the class', and help and support students. This study finds, similar to parents' perceptions of value in the school community, that 'recognition' of staff support for the school is important for school staff perceptions of being valued. School staff members feel valued if parents show appreciation for their efforts. These findings reinforce our finding regarding the importance of demonstrating appreciation and recognition of school staff efforts in the school community to support school staff participation in and commitment to the school.

\section{School Staff-Parent Partnership}

Processes related to the partnership between parents and school staff contributed to several indicators of school connectedness. This study found that parents and school staff working together contributed to the development of mutually reciprocal relationships, such as people helping each other and getting on well with each other. This contributed, in turn, to perceptions of trust and value between school staff and 
parents. Strong and positive communication between school staff and parents also contributed to the development of trust and to perceptions of being valued. Perceptions of trust and mutual reciprocity that are built between the school community and parents further influences parents' perceptions that the school environment has value for them. At the same time, respect by the school staff of families' values also contributed to school staff perceptions of value of parents in the school environment. These findings show how processes such as working together, sharing strong, positive communication, building trust and support for families, and respecting the values of families, contribute to connectedness between school staff and families in the school environment.

\section{School Staff-Student Partnership}

Characteristics of school staff and processes relevant to the school staff-student relationship made the most substantial contribution to connectedness in the school environment within the schools investigated. Staff members who could relate to students were valued highly by students in the school community. Having 'young and cool' school staff, staff with personalities that are 'fun and enjoyable', and those who can have a joke with students also contributed to students' perception that the school staff had value for them and to students' feelings of trust. School staff who demonstrated 'human' qualities, such as staff members who showed their emotions, contributed significantly to students' perception of their value, students' sense of school satisfaction, and ecological indicators of school connectedness, such as 'creating a sense of belonging to the school'. School staff who valued students 'for who they are' also contributed to students’ perceptions of being valued. 
This study identified several characteristics of school staff that were valued in all three school communities investigated: 'understanding', 'respect', 'listening to students', 'caring', 'supporting', 'interacting in a positive way', 'genuineness', and 'commitment'. All of these principles can be viewed as indicators of mutual reciprocity, but they do not promote only mutual reciprocity within the school community. They also contribute to other indicators of school connectedness, such as perceptions of being valued, feelings of trust, and school satisfaction.

\section{Whole-School Community Activity}

Other school-community partnership processes at the macro level that promoted school connectedness were related to the whole-school community activity. Processes of giving students a say in the school community and processes of student ownership of and responsibility for school activities contributed to student confidence and selfesteem, and to student perceptions that they were valued, students' sense of school satisfaction, and ecological evidence of the school 'belonging to them'. A primary school student's sense of satisfaction and engagement with the school arising from the Kids Café, is noted from the following comment:

Other times, school just has nothing going on. Now the Kid’s Café started we have something going, but half the other times it's just a school where we go to learn, but now we've got Kid’s Café with heaps going on. It’s good. (Student B)

Whole-school community activity processes also promoted perceptions of mutual reciprocity, perceptions of being valued, tolerance of diversity, and reduced bullying. 
Several of these relationships developed primarily through the mechanisms of community interaction that arose from whole-school community activities. These interactions facilitated the development of mutually reciprocal relationships by allowing school community members to 'get to know each other' and gain different insights into one another's personalities. The following quotes illustrate the interactions between students of different abilities in the special needs school case study during a 'Breakfast Tuckshop' activity, and the tolerance of diversity that gradually developed among the students:

\footnotetext{
They're up there, they're eating next to the other kids. And they're not, I mean to start off it was, 'Oh, I'm not sitting next to him, he dribbles', and things like that, but now, they don't seem to notice it quite as much. They still have their days when they're very 'getaway from me' type stuff. But, I mean they were up there this morning and they were sitting next to a boy who does an awful lot of crying and makes an awful lot of noise and they were sitting there talking...it's not something that you would see, I mean out in the playground or anywhere else around the school. They just... don’t do it. (School Staff Member C)
}

\section{Structural Aspects of the Health-Promoting School - at Class Level}

\section{Significance of Class Organisation Activities}

Two schools in this study organised whole-class activities that were 'real-life' and experiential, based on a student-centred approach, which gave students ownership over the activity, and encouraged 'hands-on' learning, while also allowing them to have fun while learning. The study found these activities to contribute to students' participation in the curriculum. 
These and other 'inclusive activities’ were an important mechanism to promote both participation in the curriculum and tolerance of diversity. The staff interviewed thought this to have occurred because students of all abilities could participate in activities together. For example, the 'real-life' nature of the Breakfast Tuckshop program, where students prepare, sell and serve breakfast to other students and staff at the special needs school, enabled all students to participate. As illustrated in the following quote, students in wheelchairs delivered menus to other students and school staff to order food:

Real-life activities open opportunities for discussion. For example, we just had student council elections, and [Student] who is in the wheelchair was elected and I am sitting at the assembly with a couple of boys and they started saying "Hey, what can she do? Why is she a student council member, she can't do anything”. And then when I said to them, (you know) talk about 'What can she do?', 'She could deliver messages around the school, she can do this, she can do that,' and they were a lot more accepting of the fact. 'Oh yes, maybe she can do something'. It opens those avenues; all of this [breakfast tuckshop] opens those avenues for talking about these situations. (School Staff Member C)

A student-centred approach to learning, such as an approach that gives a students a say in their learning, also contributed to student perceptions of being valued, school satisfaction, and such social and emotional indicators of school connectedness as students' feeling 'needed', 'included,' and 'not ignored' in the school community.

These results highlight the importance of whole-class, student-centred, and real-life teaching and learning activities in promoting school connectedness. These activities encourage participation in the curriculum, and they foster student perceptions of being 
valued, as well as students' sense of school satisfaction. These relationships were found to be the most significant at the classroom level for promoting school connectedness and are illustrated in a quote from the special needs school:

\footnotetext{
The group participation was something we were continually working on but it was just amazing how closer drawn the group became... we were sitting at the breakfast tuckshop and suddenly the teacher aide and I looked up and thought they're communicating, they're actually talking to each other, and some of them were playing, some of them were playing card games... it was just amazing to see that participation, they were actually working together, they were doing things together, because when we started the class, they hated each other and we had so many behavioural problems it was a real battle to get over the group, it was a real challenge... I guess the small things like trying to achieve something as a group, I guess that was the ultimate goal they had to get everything done for this group thing, it was a big group effort and if someone let us down, 'Oh dear'! (School Staff Member C)
}

\section{Importance of Class-Community Partnerships}

Class-community partnership structures, such as the joint coordination of a school project by two classes of different abilities and collaborative curriculum planning, contributed to various indicators of school connectedness. These partnerships influenced perceptions of mutual reciprocity, support among school staff, staff perceptions of being valued, and other ecological evidence of school connectedness, such as a 'feeling of connectedness' and a feeling 'that the community belongs together'. The importance of partnerships between classes in the development of school connectedness reinforces the importance of the 'whole-school' approach in the implementation of the HPS model to promote school connectedness. 


\section{Process Aspects of the Health-Promoting School - at Class Level}

\section{Significance of Processes of Working Together}

Class organisation processes that led to the development of school connectedness included processes in which school staff and students worked together and developed mutually reciprocal relationships. Informal school staff-student interactions that arose from these processes also gave school staff insights into students' personalities and, thereby, increased staff perceptions of value of students. Another outcome from this process was that school staff showed increased support for students, which indicates mutual reciprocity, as shown by the following quotes from a school staff member:

It's taken time, but I think there are more and more activities to show that children can do great, ... they can do wonderful things, and because teachers can see that there is a difference, they trust and support them in other ways too. (School Staff D)

The study found that processes in which students worked with one another also contributed to indicators of mutual reciprocity, such as when students helped and cared for each other, as well as to ecological indicators of school connectedness, such as reports that students were working together 'more cohesively as a group'. These processes in which students worked together also helped to develop student friendships, and to promote tolerance of diversity among students.

These findings demonstrate the importance of cooperative learning activities on school connectedness, and they illustrate how these processes can bridge the gap 
between school staff and students. This is an important advance in our theoretical understanding of school connectedness.

\section{Significance of Class-Community Partnerships}

Within the context of the whole-school community activity, class-community partnerships between different classes within the school and between classes and school community members contributed to school connectedness. Partnerships between different classes in the context of a whole-school community activity offered students the opportunity to develop insight into other students' personalities and get to know them better. This contributed to the development of tolerance of diversity within a class, which also affected other classes in the context of the 'whole-school community activity’ discussed above.

\section{Discussion and Conclusion}

Several new theoretical developments have emerged from the conceptual framework developed and explored in this research, demonstrating how a comprehensive wholeschool approach such as the HPS model can promote school connectedness.

The 'whole-school' emphasis of the model illustrates the powerful strengthening influence of such an approach, since it provides opportunities for supportive interaction throughout the school community, including between and within classes. This central finding of the research supports and validates the use of a whole-school approach for promoting connectedness, and it provides refreshing insight into the 
three levels of influence of a whole-school approach: at the school, class, and schoolclass interface, such as the bonds that can form between classes and between classes and the school community.

The most significant finding of this research is the identification of 'whole-school community activities' as a vehicle for developing interaction across all levels of the school community at the school, class, and school-class interface. Whole-school social, celebratory days, and activities that promoted direct connection between students and the school physical environment (for example, through students engraving pavers with their names and artwork), provided powerful influences on school connectedness. By identifying the importance of whole-school community activities that involve all groups, including students, school staff, parents and families, and health services and community agencies, this study provides a substantial theoretical development to understanding approaches for promoting school connectedness.

Whole-school community activities crossed the school-class interface by promoting class-community partnerships that encouraged links between classes, links to other school staff, as well as partnerships with parents and health and community agencies. All of this contributed to school connectedness. This finding represents another advance in our understanding of the mechanisms for promoting connectedness. Specific structures that support the development of these relationships, such as collaborative curriculum planning between classes in the context of a whole-school community activity confirms others' findings that team teaching efforts create strong relationships among school staff (Hunt et al., 2000; Kugelmass, 2001; Weller, 2000). 
The finding that whole-school activities involving whole classes working together contributes to school connectedness represents a third advance in theory that expands and builds on other approaches shown to build connectedness, such as small group work, class discussions, and shared tasks (Barker et al., 1997; Korinek, et al., 1999; Patton et al., 2006). It reinforces the importance of recognising the whole class as a social structure in which to promote connectedness. This study has shown that student-centred and real-life learning activities are instrumental in providing opportunities for students and members of the school community of all abilities and backgrounds to work together and get to know one another better; in addition, this study concurs with previous work to indicate that these activities nurture the formation of social relationships in an everyday or 'real-life' context (Patton et al., 2006).

The present study has identified a range of school policy and organisational structures that can influence school connectedness, such as multi-strategic approaches to prevent bullying, peer support programs, extra-curricular activities, support structures for school staff, and a fair behaviour management system. These findings support and further our understanding of the importance of a whole-school approach for fostering connectedness, which is well documented in the literature (Bauer et al., 2007; Korinek et al., 1999; Patton et al., 2006). Among the findings of this study, the identification of the importance of a welcoming school environment is a fourth theoretical advance. The importance of this factor reflects the contribution to connectedness that can come from a school social environment where school staff are friendly, welcoming, and approachable, and from a physical environment, such as a 
small campus, that promotes the connectedness of parents and community to the school.

This research reinforces the recognition of the significance of partnerships in the school community, and in particular it highlights the influence of the relationship between students and school staff along several indicators of school connectedness, including mutual reciprocity, perceptions of value, trust, school satisfaction, reduced absenteeism, and even reduced bullying and aggressiveness in the school environment. These findings support the current literature (Baker et al., 2003; Ma, 2003; Murray-Harvey and Slee, 2007; Smith and Sandu, 2004) and build on existing understanding by identifying the key elements that initiate and sustain these partnerships, not only between school staff and students, but also between school staff and the broader school community, such as parents.

This research has contributed to the theoretical understanding of how to promote school connectedness and it argues for a whole-school approach, embodied by the HPS model, for building school connectedness. The conception of school connectedness as an ecological concept, which draws upon social cohesion and social capital (Kawachi and Berkmann, 2000) for its theoretical basis, represents a conceptual development in the fields of sociology, public health, and education. This ecological conceptualisation, along with qualitative research methodologies, was necessary in the present study in order to explicate the mechanisms that link a comprehensive model and school connectedness. The main limitation of this study is the exploratory nature of the research design and approach, which limited the number of schools and phenomena that could be investigated. As a result, the theoretical 
developments offered by this research are a starting point for further exploration. More research is needed to determine other phenomena related to the 'whole-school' emphasis of a comprehensive approach, and in particular to explore its links to the physical environment. The present study suggests that this line of research will be fruitful.

A focus on the interactions of a whole-school approach across all levels of the school community at the school, class and school-class interface, rather than merely investigating the individual components of the approach, needs to be considered in further research to elucidate phenomena to promote connectedness. This research has demonstrated that the powerful influence of the HPS model on school connectedness is more than the sum of its parts. The research has provided an important contribution to an understanding of the mechanisms involved in promoting school connectedness, which has positive effects on the health, education, and social well-being of children and young people. 


\section{References}

Baker, J. A., Dilly, L.J., Aupperlee, J.L. and Patil, S.A. (2003), “The developmental context of school satisfaction: schools as psychologically healthy environments”, School Psychology Quarterly, Vol. 18 No. 2, pp. 206-221.

Barker, J.A., Terry, T., Bridger, R. and Winsor, A. (1997), "Schools as caring communities: a relational approach to school reform”, School Psychology Review, Vol. 26 No. 4, pp. 586-603.

Battistich, V., Schaps, E. and Wilson, N. (2004), "Effects of an elementary school intervention on students' “connectedness” to school and social adjustment during middle school”, Journal of Primary Prevention, Vol. 24 No. 3, pp. 243262.

Bauer, N.S., Lozano, P. and Rivara, F.P. (2007), "The effectiveness of the Olweus bullying prevention program in public middle schools: a controlled trial”, Journal of Adolescent Health, Vol. 40, pp. 266-274.

Bisset, S., Markham, W. and Aveyard, P. (2007), "School culture as an influencing factor on youth substance use”, Journal of Epidemiology and Community Health, Vol. 61, pp. 485-490.

Bond, L., Butler, H., Thomas, L., Carlin, J., Glover, S., Bowes, G. and Patton, G. (2007), "Social and school connectedness in early secondary school as predictors 
of late teenage substance use, mental health, and academic outcomes”, Journal of Adolescent Health, Vol. 40, pp. 357.e9-357.e18.

Carter, M., McGee, R., Taylor, B. and Williams, S. (2007), "Health outcomes in adolescence: associations with family, friends and school engagement”, Journal of Adolescence, Vol. 30, pp. 51-62.

Clift, S. and Bruun Jensen, B. (Eds), (2006), The Health Promoting School International Advances in Theory, Evaluation and Practice, Danish University of Education Press, Copenhagen.

Hawkins, J.D., Kosterman, R., Catalano, R.F., Hill, K.G. and Abbott, R.D. (2005), "Promoting positive adult functioning through social development intervention in childhood. Long-term effects from the Seattle social development project”, Archives of Pediatric and Adolescent Medicine, Vol. 159, pp. 25-31.

Hunt, P., Hirose-Hatae, A., Doering, K., Karasoff, P. and Goetz, L. (2000), ““Community” is what I think everyone is talking about”, Remedial and Special Education, Vol. 21 No. 5, pp 305-317.

Kawachi, I. and Berkmann, L. (2000), “Social cohesion, social capital and health”, in Berkmann, L. and Kawachi, I. (Eds), Social Epidemiology, Oxford University Press, New York, pp. 174-190. 
Kliewer, W. and Murrelle, L. (2007), "Risk and protective factors for adolescent substance use: findings from a study in selected Central American countries”, Journal of Adolescent Health, Vol. 40, pp. 448-455.

Korinek, L., Walther-Thomas, C., McLaughlin, V. and Williams, B. (1999), “Creating classroom communities and networks for student support”, Intervention in School and Clinic, Vol. 35 No. 1 pp. 3-9.

Kugelmass, J. W. (2001), “Collaboration and compromise in creating and sustaining an inclusive school”, International Journal of Inclusive Education, Vol. 5 No. 1, pp. 47-65.

Lochner, K., Kawachi, I. and Kennedy, B. (1999), "Social capital: a guide to its measurement”, Health \& Place, Vol. 5, pp. 259-270.

Lonczak, H.S., Abbott, R.D., Hawkins, J.D., Kosterman, R. and Catalano, R.F. (2002), "Effects of the Seattle social development project on sexual behaviour, pregnancy, birth, and sexually transmitted disease outcomes by age 21 years”, Archives of Pediatric and Adolescent Medicine, Vol. 156, pp. 438-447.

Ma, X. (2003), “Sense of belonging to school: Can schools make a difference”, The Journal of Educational Research, Vol. 96 No. 6, pp. 340-349.

Miles, M. and Huberman, A. (1994), Qualitative Data Analysis, An Expanded Sourcebook, 2nd edn, Sage Publications, California. 
Murray-Harvey, R. and Slee, P. (2007), "Supportive and stressful relationships with teachers, peers and family and their influence on students' social/emotional and academic experience of school”, Australian Journal of Guidance \& Counselling, Vol. 17 No. 2, pp. 126-147.

Onyx, J. and Bullen, P. (2000), "Sources of social capital”, in Winter, I. (Ed.), Social Capital and Public Policy in Australia, Australian Institute of Family Studies, Melbourne, pp.105-135.

Patton, G. (1990), Qualitative Evaluation and Research Methods, 2nd edn, Sage Publications, California.

Patton, G.C., Bond, L., Carlin, J.B., Thomas, L., Butler, H., Glover, S., Catalano, R. and Bowes, G. (2006), "Promoting social inclusion in schools: a randomized trial of effects on student health risk behaviour and well-being”, American Journal of Public Health, Vol. 96 No. 9, pp. 1582-1587.

Patton, G.C., Glover, S., Bond, L., Butler, H., Godfrey, C., Di Pietro, G. and Bowes, G. (2000), “The Gatehouse project: a systematic approach to mental health promotion in secondary schools”, Australian and New Zealand Journal of Psychiatry, Vol. 34, pp. 586-593. 
Pittman, L. and Richmond, A. (2007), “Academic and psychological functioning in late adolescence: the importance of school belonging”, The Journal of Experimental Education, Vol. 75 No. 4, pp. 270-288.

Putnam, R. (1995), “Bowling alone: America’s declining social capital”, Journal of Democracy, Vol. 6 No. 1, pp. 65-78.

Resnick, M. D., Bearman, P. S., Blum, R. W., Bauman, K. E., Harris, K. M., Jones, J., Tabor, J., Beuhring, T., Sieving, R. E., Shew, M., Ireland, M., Bearinger, L. H. and Udry, J. R. (1997), “Protecting adolescents from harm: findings from the national longitudinal study on adolescent health”, Journal of the American Medical Association, Vol. 278 No. 10, pp. 823 - 832.

Rowe, F., Stewart D. and Patterson, C. (2007), “Promoting school connectedness through whole school approaches”, Health Education, Vol. 107 No. 6, pp. 524 542.

Rutter, M., Maughan, B., Moretimore, P., Ouston, J. and Smith, A. (1979), Fifteen Thousand Hours: Secondary Schools and Their Effects on Children, Open Books, London.

Shochet, I., Smyth, T. and Homel, R. (2007), “The impact of parental attachment on adolescent perception of the school environment and school connectedness”, Australia \& New Zealand Journal of Family Therapy, Vol. 28 No. 2, pp. 109-118. 
Smith, D.C. and Sandhu, D.S. (2004) "Toward a positive perspective on violence prevention in schools: building connections", Journal of Counseling and Development, Vol. 82 No. 3, pp. 287-293.

Springer, A., Parcel, G., Baumler, E. and Ross, M. (2006), "Supportive social relationships and adolescent health risk behavior among secondary school students in El Salvador”, Social Science \& Medicine, Vol. 62, pp. 1628 - 1640.

Stewart, D. (2008), “Implementing mental health promotion in schools: a process evaluation”, International Journal of Mental Health Promotion, Vol. 10 No. 1, pp. $32-41$.

Sun, J. and Stewart, D. (2007), "How effective is the health-promoting school approach in building social capital in primary schools?”, Health Education, Vol. 107 No. 6, pp. 556-574.

Thompson, D., Iachan, R., Overpeck, M., Ross, J. and Gross, L. (2006), "School connectedness in the health behaviour in school-aged children study: the role of student, school, and school neighbourhood characteristics”, Journal of School Health, Vol. 76 No. 7, pp. 379-397.

Weller, D. R. (2000), “Block scheduling and inclusion in a high school”, Remedial \& Special Education, Vol. 21 No. 4, pp. 209-219. 
Wilkinson, R. (1996), Unhealthy Societies. The Afflictions of Inequality, Routledge, London and New York.

Yin, R. (1994), Case Study Research Design and Methods, 2nd edn, Sage Publications, London.

Youngblade, L., Theokas, C., Schulenberg, J., Curry, L., Huang, I. and Novak, M. (2007), "Risk and promotive factors in families, schools and communities: a contextual model of positive youth development in adolescence”, Pediatrics, Vol. 119 No. 2, pp. s47-s57. 